\title{
DIFICULDADES DA DOCÊNCIA NO CENÁRIO DIGITAL: CONTORNOS E PRÁTICAS DE SALA DE AULA
}

\author{
Erika Giacometti-Rocha Berribili ${ }^{1}$ \\ Daniel Mill ${ }^{2}$ \\ Maria Iolanda Monteiro ${ }^{3}$ \\ Rafaela Marchetti ${ }^{4}$
}

\begin{abstract}
Resumo: Consideradas sine qua non da interação professor-aluno em sala, as disciplinas sempre foram um problema no Brasil, muito antes das TDIC fazerem parte da realidade da sala de aula. Portanto, em um primeiro momento, procurou-se elucidar os entraves para transformação na instituição escolar estruturada no contexto da globalização. Em seguida, pelo conceito de mídia-educação, pensou-se o conteúdo curricular na era da informação. Por fim, abordou-se a relação professor-aluno mediada por TDIC. Nessa tríade - contexto, conteúdo e relação professor-aluno -, mostraram-se pontos de vista e uma reflexão para as dificuldades práticas dos docentes na sala de aula em meio à cultura digital.
\end{abstract}

Palavras-chave: Cultura digital. Sala de aula. Docência. Dificuldades.

\section{DIFFICULTIES OF TEACHING IN THE DIGITAL SCENARIO: CONTOURS AND PRACTICES OF CLASSROOM}

\begin{abstract}
: considered sine qua non of the teacher-student interaction in the classroom, the disciplines have always been a problem in Brazil long before the digital media as part of the reality of the classroom. Therefore, at first, we tried to elucidate the obstacles to transformation in the structured school institution in the context of globalization. Then, by the concept of media-education, curriculum content was thought in the information age. Finally, the teacher-student relationship mediated by digital media was addressed. In this triad - context, content and teacher-student relationship - it was shown points of view and a reflection on the practical difficulties of teachers in the classroom in the midst of digital culture.
\end{abstract}

Keywords: Digital culture. Classroom. Teaching. Difficulties.

\footnotetext{
1 Doutoranda em Educação (PPGE) na Linha Educação, Cultura e Subjetividade pela UFSCar (2016). Mestrado em Ciência Tecnologia e Sociedade (PPGCTS) na Linha Linguagem, Comunicação e Ciência pela UFSCar (2013-2015). Pesquisa sobre o Impacto sociocultural e cognitivo das Tecnologias Digitais de Informação e Comunicação com fomento da Capes (Coordenação de Aperfeiçoamento de Pessoal de Nível Superior) concluído. Graduação em Letras-Francês pela Universidade Estadual Paulista Júlio de Mesquita Filho - UNESP (1998-2002). Integrante do Grupo Horizonte (Grupo de Estudos e Pesquisas sobre Inovação em Educação, Tecnologias e Linguagens). Integrante do Grupo de Teoria Crítica e Educação da UFSCar. Tutora Virtual na SEaD - UFSCar e Professora no Curso de Especialização Edutec-SEaD/UFSCar.

${ }^{2}$ Especialização em Educação e Tecnologias.

${ }^{3}$ Graduação em Pedagogia pela Universidade Estadual Paulista Júlio de Mesquita Filho, mestrado em Educação Escolar pela Universidade Estadual Paulista Júlio de Mesquita Filho e doutorado em Educação pela Universidade de São Paulo. Tem experiência na área de Educação, com ênfase em métodos e técnicas de ensino, atuando, principalmente, nos seguintes temas: práticas e saberes docentes, êxito e fracasso escolar, alfabetização, letramento, variação linguística, educação a distância, formação inicial e continuada de educadores da educação básica. Realizou pós-doutorado na Faculdade de Educação da Universidade de Campinas. Professora Adjunta III da Universidade Federal de São Carlos, atuando no curso de Licenciatura em Pedagogia na modalidade presencial e a distância.

4 Possui graduação em Licenciatura Em Pedagogia pela Universidade Estadual Paulista (UNESP de Araraquara), mestrado em Educação pela Universidade Federal de São Carlos/UFSCAR e doutoranda em Educação na linha de pesquisa Educação, Cultura e Subjetividade no PPGE da Universidade Federal de São Carlos/UFSCAR. Cursou três especializações: uma, em Educação Infantil pela Universidade Federal de São Carlos (UFSCAR); outra em Alfabetização e letramento pela Faculdade São Luís/Jaboticabal; e a outra, em Educação Especial com ênfase em Deficiência Intelectual pela Faculdade São Luís/Jaboticabal. Participa do Grupo de Pesquisas GEPEPDH (Grupo de Estudos e Pesquisas em Educação: Participação Democrática e Direitos Humanos).
} 


\section{INTRODUÇÃO}

Os professores contribuem com seus saberes, valores, suas experiências nessa complexa tarefa de melhorar a qualidade social da escolarização. Essa questão envolve formação inicial e continuada, articulada a um processo de valorização identitária e profissional dos professores.

No cenário da cultura digital, surgem inovações técnicas para os dispositivos digitais, hoje muito mais úteis e funcionais que os computadores de mesa no começo da década de 1990. Com a expansão do acesso à banda larga, a educação brasileira depara-se com o ambiente na educação, e esse processo de identidade e profissionalização dos professores passa por mudanças.

Agora, estudantes podem estar em uma sala e saber o que está acontecendo nesse instante na Síria numa aula de Geografia Política e, ao mesmo tempo, conversar com o colega sobre comentário do professor, ao passo que a mãe manda mensagem avisando que deixará a chave da casa com a vizinha. O mesmo estudante, ao entrar no ônibus, acessa o site que o professor sugeriu.

As possibilidades comunicativas e de acesso às informações tornaram-se, assim, ubíquas, porque a multidimensionalidade do espaço é inseparável da hipermobilidade, termo que Santaella (2013, p. 15) explica como sendo "a mobilidade física acrescida dos aparatos móveis que nos dão acesso ao ciberespaço".

No dia a dia escolar, que pese as escolas públicas serem contempladas com programas de informática para uso pedagógico, segui-los exige enfrentar muitos percalços, segundo educadores. Entre as dificuldades, a suposta perda de controle da “disciplina" e da atenção dos alunos.

Este artigo propõe abrir a reflexão para as práticas na sala de aula e, por isso, apresenta a educação brasileira procurando elucidar as dificuldades que o professor enfrenta nas escolas com a presença das TDIC.

Em uma breve introdução ao sistema escolar, procura-se elucidar as raízes dos entraves para transformação do modo como a escola é estruturada e do contexto em que está inserida: a globalização. Essa raiz reflete em parte a concepção que o professor adota em seu trabalho com os alunos.

Em seguida, aborda-se o conceito de mídia-educação para pensar o conteúdo em sala na era da informação. Esse conceito surge com a propagação dos meios de massa do século anterior e hoje continuam presentes com as TDIC que acoplam 
esses meios, embora com novas considerações ligadas ao domínio prático e teórico dessas tecnologias.

Por fim, abordamos também a teoria do meio de Meyrowitz (1985) para ponderar a relação professor-aluno quando mediada por uma TDIC. Nessa teoria, o autor aproxima a relação comunicativa a um palco, em que as pessoas exercem papéis que determinam os sistemas de informação que serão veiculados.

Assim, nessa tríade - estrutura institucional, trabalho do conteúdo curricular e relação professor-aluno -, mostram-se pontos de vista sobre algumas dificuldades da aliança da cultura digital com o exercício da educação em sala de aula.

\section{METODOLOGIA}

Este trabalho foi fruto de uma pesquisa de natureza descritiva que usou métodos quantitativos que não tratamos aqui. Também foi usado o qualitativo, através de entrevistas. Três professores foram entrevistados, dois aparecem no artigo. O recurso utilizado foi um gravador de áudio e a transcrição feita manualmente.

TABELA 1 - Perfil dos entrevistados considerados nesse artigo.

\begin{tabular}{cccc}
\hline Função & Tipo de escola & Sexo & Idade \\
\hline Professor A & Públicas & Masculino & 42 \\
\hline Professor B & Públicas e Privadas & Masculino & 28
\end{tabular}

O objetivo da entrevista era recolher dados para uma análise do impacto sociocultural e cognitivo das tecnologias digitais de informação e comunicação no âmbito da educação de adolescentes. Os professores faziam parte de dados que seriam contrapostos aos dos estudantes entre 14 e 16 anos que usavam intensamente a internet, os alvos da pesquisa.

\section{COMO O SISTEMA ESCOLAR BRASILEIRO DESEMBOCA NO TRABALHO DOCENTE EM SALA DE AULA}

Conforme lembra Santaella (2013), atravessa-se um novo estágio do capitalismo global chamado, por alguns, de pós-industrialismo e, por outros, de informacionismo.

Charlot $(2014,2008)$ descreve bem as contradições inerentes ao trabalho do professor nessa atualidade e toca na questão da presença de novas tecnologias. 
Segundo o autor, até a década de 50 do século XX, a escola não abre perspectivas profissionais e não promete ascensão social, com exceção de uma pequena minoria. Os jovens oriundos da classe média continuam estudando além da escola primária, mas, na maioria das vezes, esses estudos os levam às posições sociais a que já eram destinados.

Se alunos fracassavam, esse fracasso não acarreta consequências dramáticas, assim, não é objeto de debate social. Debate-se apenas o acesso à escola e a contribuição do ensino para a modernização do país.

As questões da qualidade, da adaptação à demanda e, por conseguinte, da flexibilidade, da diversidade, da velocidade de reação se tornaram essenciais. Para enfrentar esses desafios novos, novas tecnologias informáticas e eletrônicas foram usufruídas, mas também novas formas de gestão da mão de obra implantadas.

Desse modo, na produção de mercadorias ou de serviços com alto valor agregado, é preciso uma mão de obra que se engaje no seu trabalho com seriedade, dedicação, senso de responsabilidade, identificação com a empresa, inteligência e criatividade, o que vai refletir diretamente na maneira como a educação é vista.

Segundo Charlot (2014), a empresa recupera os produtos da imaginação do trabalhador através de círculos de qualidade e demais dispositivos e, logo, o que era invento pessoal, marco da singularidade, da dignidade e, muitas vezes, da resistência do trabalhador toma forma de nova regra formal imposta a todos. Assim, Charlot (2014, p. 41) denuncia que "a relação entre trabalho e educação continua sendo permeada pela ameaça da exploração e da alienação", ao contrário da educação que emancipa, como se prega nas escolas.

Para Saviani, o paradoxo reside no papel de a escola formar para o exercício consciente da cidadania pela ação educativa, contando com cidadãos ativos, críticos e transformadores, mas com um desejo interno de que esses mesmos cidadãos sejam “dóceis, colaboradores, compreensivos das diferenças e desigualdades, respeitosos da ordem social e conformados à situação vigente; submissos, portanto, às normas e valores próprios da sociedade tal como se encontra constituída" (SAVIANI, 2017, p. 655).

Para ele, ainda, a razão de tornar impossível a democracia pela educação deve ser buscada na estrutura da sociedade burguesa que deslocou o eixo do processo produtivo do consumo para a troca, convertendo-se numa imensa engrenagem produtora de mercadorias.

Dessa forma, considera que, nessa sociedade, defrontam-se, no mercado, proprietários aparentemente iguais, mas de fato desiguais, realizando, sob a aparência da 
liberdade, a escravização do trabalho ao capital. O trabalhador, se não vender sua força de trabalho ao capitalista, não terá como sobreviver e, por isso, não vê escolha. Ou vende sua força de trabalho ou morre ou, ainda, resta apenas a alternativa da delinquência.

Efetivamente, nas sociedades escravista e feudal, as relações sociais eram transparentes, já que o escravo era, no plano da realidade e no plano da concepção, de fato e de direito, propriedade do senhor; e o servo, por sua vez, estava submetido ao senhor e devia servi-lo, também, de fato e de direito, real e conceitualmente.

Saviani explica que,"enquanto o capitalista é livre na aparência e na essência, de direito e de fato, formal e materialmente, o trabalhador é livre apenas na aparência, no plano do direito e no aspecto formal" (2017, p. 659). Sendo assim, em essência, factualmente e materialmente, ele é escravo.

E explica outro paradoxo decorrente do processo descrito: o cidadão autônomo, sujeito de direitos e deveres, consciente e participante ativo na vida da sociedade é o homem abstrato, o "verdadeiro" homem. O cidadão real é o homem em sua existência sensível, o indivíduo "egoísta", adaptado, submisso à sociedade burguesa tal como se encontra constituída.

Charlot (2014) discute, ainda, os métodos educacionais quanto ao significado exato da "sociedade do saber", ou "sociedade do conhecimento". Segundo o autor, os processos de produção e de consumo contemporâneos incorporam cada vez mais conhecimentos.

Ao mesmo tempo, o autor sustenta a ideia de que não precisamos de muito conhecimento para utilizar os objetos e os serviços da vida moderna: "não é necessário conhecer Eletrônica para usar um computador ou um cartão bancário, bem como não é útil estudar Ótica para olhar através de óculos. Há muito saber incorporado no mundo em que vivemos, mas temos com ele uma relação mais mágica do que cognitiva" (CHARLOT, 2014, p. 41).

Os sujeitos, rodeados diariamente por tecnologias, também percebem a necessidade do conhecimento. Esse contexto corrobora com o que Castells (1999) afirma ser: o princípio de acumular conhecimentos usados para gerar mais conhecimento, tendo como consequência a modelação do comportamento social. Passa a ser fundamental também preparar produtores de conhecimento.

A globalização trouxe à escola contemporânea, portanto contradições estruturais que envolvem a função de a escola se mesclar a um ambiente de amplo crescimento das mídias, do audiovisual, da web, com ampliação do universo da comunicação, da informação e da midiatização. 
Dessen e Polonia (2007) propõem repensar o uso de estratégias didáticas conforme realidades distintas - a dos adolescentes e professores -, assim como responder às demandas da comunidade e aos recursos disponíveis, levando em conta as condições e peculiaridades de cada época ou momento histórico.

Se é preciso repensar as peculiaridades de cada sujeito, consideramos fundamental observar igualmente o contexto e a inserção de algumas TDIC, não somente aquelas fomentadas pelo Estado como também os dispositivos digitais cada dia mais sofisticados e com diversas funções nas mãos de jovens e adolescentes, ávidos por manipulá-los.

Ademais, a cooperação técnica e financeira ao setor educacional oferecida pelo Banco Mundial, que data desde a década de 1970, reforça o que Charlot (2014) e Saviani $(1999,2017)$ defendem sobre as contradições das finalidades da educação. Tommazi, Warde e Haddad (2000) acrescentam que essa cooperação incide em princípios neoliberais nas orientações de reformas educacionais, fazendo com que a educação seja competitiva e produtiva - sintonizada com as demandas das empresas e das indústrias.

Para Charlot, parece fundamental colocar a questão da qualidade da escola, visando ao aprimoramento do ensino e à modernização da formação dos jovens e da própria escola (CHARLOT, 2014). Por outro lado, o autor afirma que, em vez de considerar a qualidade, a eficiência e a eficácia das lógicas neoliberais e nefastas, pode-se pensa-las como não abusivas, restando saber o que significam as palavras qualidade e eficácia na escola.

Para ele, num contexto neoliberal, a ideia é preparar plenamente as subjetividades e potencialidades, não simplesmente orientar sujeitos que meramente atendem a demandas de "mercados". Assim, acrescentamos pensar no cuidado que devemos ter ao selecionar as tecnologias e recursos nele permitidos para o uso.

Alguns autores nos apresentaram um esboço do que significaria o impacto da mídia para o sistema escolar. Meyrowitz (1985), por exemplo, defende a insustentabilidade do sistema de ensino tal como ele é na era eletrônica, pois este nascera na era impressa. Ele defende que foi na era impressa que apareceu o nosso sistema seriado e especializado.

O sistema impresso possibilitou que as escolas fossem um sistema provedor de conhecimento. Com o material impresso, era possível manter o "segredo" revelado apenas na série seguinte. Os livros reservados aos "adultos" poderiam ser conservados longe das crianças. 
No que concerne à TV, na década de 1980, para Meyrowitz (1985), possuir uma em casa era sinônimo de crianças e adolescentes terem, algumas vezes, um número maior de informações do que os professores. É por isso que o autor acredita que dividir os alunos por idade é pouco eficaz.

Com as TDIC e suas inúmeras possibilidades de acesso a todo tipo de informação veiculadas em blogs, sites de museus, bibliotecas online e inúmeros vídeos educativos, a afirmação de Meyrowitz (1985) é pertinente ainda hoje.

Se usamos recursos de aplicativos, sites e plataformas que lucram com o ensino ou se usamos tecnologias que se tornam obsoletas tão logo surjam novos recursos ou ainda se acessamos vídeos no youtube que permitem a monetarização do que é veiculado conforme o número de acessos, como não podemos pensar na relação entre a metodologia escolhida e a subjetividade que por ele é produzida?

Basta de pensar em um vídeo educacional produzido por alguém que pretende alcançar um número de visualizações maior, com certeza será muito diferente de um que pretenda discutir um conceito complexo e que requer uma abordagem mais detalhada. Outro exemplo reside no uso de um software livre e um pago, que também diferem no modo pelo qual uma escola ou professor organiza as suas aulas. E os algoritmos de busca e seleção de conteúdo utilizados pelo Google e pelas principais redes sociais, capazes de informar ao mercado os seus interesses ou então criar bolhas políticas?

Considerando esses pontos, devemos pensar que princípios neoliberais na educação estão também diretamente relacionados ao que é veiculado na cultura digital. Desse modo, também o professor tem de atentar para os objetivos que deseja atingir com o uso dos conteúdos e recursos dos quais dispõe.

Por essa razão, pensar em questões ontológicas passa por dominar o entendimento do significado das questões metodológicas no "lidar com as tecnologias", independentemente da época em que surjam.

\section{A MÍDIA-EDUCAÇÃO E A TEORIA DO MEIO DE MEYROWITZ COMO PERSPECTIVA}

Desde que os primeiros canais de comunicação analógicos surgiram, iniciaram-se estudos sobre a origem, a influência e os efeitos dessas tecnologias. Entre esses estudos, surge a Teoria da Comunicação, que engloba a psicologia, a filosofia e a sociologia e vem para compreender a experiência do totalitarismo na Europa. A Mídia-educação vem a ser os estudos dos efeitos das mídias na educação, com base nessa teoria comunicativa. 
No Brasil, o conceito Mídia-Educação aparece em organismos internacionais a partir da década 1960. Primeiro, referia-se à capacidade destes novos meios de comunicação alfabetizarem grande escala de populações carentes de recursos e, também, qualificar profissionais (BÉVORT; BELLONI, 2009; FANTIN; RIVOLTELLA, 2012).

A mesma expressão é usada quando se discute a preocupação de educadores, intelectuais e decisores com a influência cultural midiática, com os riscos de manipulação política, comercial e publicitária e com a consequente necessidade de desenvolver abordagens críticas (GONNET; BELLONI, 2004).

Em sua fase pioneira, nos anos entre as décadas de 1950 a 60 , o interesse pela mídia-educação cresce, ao passo que os outros aspectos dos conteúdos midiáticos (ficção e entretenimento) vão revelando sua eficácia comunicacional e passam a integrar a preocupação ideológica. Entretanto, é notória a preponderância na informação em muitas propostas e ações de mídia-educação. Os perigos de influência ideológica levaram depois jornalistas e educadores a uma leitura crítica sobre o conteúdo repleto de artimanhas da comunicação em massa (BELLONI, 2012).

Hoje, de acordo com Bévort e Belloni (2009, p. 1098), a proposta da Mídia-Educação passa a ser a “apropriação dos modos de operar máquinas que abrem as portas do mundo encantado da rede mundial de computadores, possibilitando a todos se tornarem produtores de mensagens midiáticas".

Por outro caminho, o movimento do grupo continua focando na antiga "leitura crítica de mensagens", mas acrescenta, a seu papel, a análise de ferramenta pedagógica, que diz respeito às situações de aprendizagem, à integração e aos processos educacionais. Do ponto de vista conceitual, a questão mais importante é a inserção destes dispositivos técnicos aos processos educacionais e comunicacionais (FANTIN; RIVOLTELLA, 2012).

Entretanto, todos esses esforços de reflexão carecem de uma sistematização que torne possível uma análise mais objetiva. Entre diversas pesquisas realizadas no campo da mídia-educação, conforme sua recente atuação, há observação da interação aluno-professor, mas não há uma sistematização capaz de permitir compreender a complexidade das interações sociais nesse contexto.

Trata-se, antes de tudo, de um problema em que diversos pesquisadores insistem em definir em termos apenas do consumo ou literacia para inclusão. Muito válido e complementar por sinal, mas precisamos de uma análise que explique a dinâmica de interação professor e aluno mediados ou em presença das TDIC. Nesse sentido, 
Meyrowitz (1985) parece ser um bom começo para oferecer uma perspectiva objetiva no sentido da dinâmica de comunicação na sala de aula ${ }^{5}$.

Meyrowitz (1985) empresta a metáfora do drama para explicar os sistemas de informação em um dado ambiente. De acordo com essa metáfora, sugere que o comportamento de um indivíduo, em uma determinada configuração, pode ser dividido em: back region, ou comportamento nos bastidores, e frontal region, ou comportamento no palco. Em frontal region, os artistas estão na presença de seu "público" para um papel particular, e eles representam uma concepção relativamente ideal de um papel social. Para ilustrar, o autor exemplifica:

Os garçons, por exemplo, estão em uma região da frente quando eles servem pessoas em uma sala de jantar restaurante. Nreo frontal, garçons são geralmente educados e respeitosos. Sua aparência e forma é uma de limpeza e eficiência. Eles não entram nas conversas do jantar de clientes do restaurante. Eles não comentam sobre os hábitos alimentares de seus clientes ou maneiras à mesa. Eles raramente, ou nunca, comem enquanto os clientes olham (MEYROWITZ, 1985, p. 29, tradução nossa) ${ }^{6}$.

Assim, conforme este autor, ocorre uma espécie de "gerenciamento de impressão", servindo, portanto, como uma abreviação social, através da qual as pessoas se identificam e fornecem expectativas sobre o seu comportamento, tanto para os outros, como para si mesmos. Ele acrescenta que, dependendo da situação, podemos até misturar comportamentos e criar uma nova situação, que seria o meio termo desses dois comportamentos: o middle region.

Conforme o tipo de mediação, a linha divisória entre os comportamentos característicos de cada região pode ser alterada. Por isso, insiste que o ambiente físico por ele mesmo não determina a natureza das interações, mas os modelos de fluxo de informação, podendo a discussão ser removida completamente da questão da presença física para ser focada, exclusivamente, no acesso à informação (MEYROWITZ, 1985).

"Informação" é usada pelo autor em um sentido especial para significar informação social: tudo o que as pessoas são capazes de saber sobre o comportamento e das ações de si e das outras. O termo refere-se àquelas "coisas" nebulosas que aprendemos uns com os outros em atos de comunicação.

\footnotetext{
${ }^{5}$ A dinâmica de comunicação na sala de aula assume o caráter de prática escolar, visto que as atividades de comunicação integram as práticas de ensino dos professores.

${ }^{6}$ Waiters, for example, are in a front region when they serve people in a restaurant dining room. In the front region, waiters are usually polite and respectful. Their appearance and manner is one of cleanliness and efficiency. They do not enter into the dinner conversations of restaurant patrons. They do not comment on their customers' eating habits or table manners. They rarely, if ever, eat while in the sight of patrons.
} 
Meyrowitz (1985) ainda estava presente num contexto em que dispositivos de comunicação digitais mais ou menos móveis ainda não eram uma realidade. Contudo, essas mídias acoplam em si as diversas mídias anteriormente analisadas pelos teóricos da mídia, portanto suas análises podem ser consideradas muito pertinentes.

A analogia que o autor faz ajuda a compreender: ver televisão é um pouco como ver as pessoas através de um espelho unidirecional em uma situação em que as pessoas sabem estar sendo observadas por milhões de outras pessoas em cubículos isolados; rádio é como ouvir as pessoas através de uma porta ou parede com uma consciência similar por parte dos participantes; e assim por diante.

Os sites de busca e as redes sociais hoje muito usados por professores e que determinam o que será veiculado em cada página ou linha do tempo acessada exige entender a diferença entre navegar por uma rede com algoritmos e uma sem. Isso pode ser importante para compreender o significado deste recurso.

Embora redes sociais argumentem ser possível proporcionar melhores resultados para os seus frequentadores quando são considerados outros fatores além do horário da postagem, devemos lembrar o motivo financeiro por trás dessa mudança.

Quem compra espaço nas redes sociais garante que suas postagens serão vistas por muito mais pessoas em um determinado período de tempo. Por essa razão, os algoritmos nem sempre garantem os favoritos na experiência dos usuários e não seria nada difícil para uma rede social tão usada mundialmente, como o Facebook, garantir as eleições de um candidato específico.

Consequentemente, no campo escolar, se um professor usa determinada plataforma e o aluno também, existem essas questões importantes a serem consideradas. Ao mesmo tempo, essas questões explicam a dificuldade de se instituir uma visão crítica com tantos recursos que levam ao empobrecimento da visão crítica do professor e do aluno. Se não houver o conhecimento de como um site de busca ou rede funciona, mídias sociais e as tecnologias desenvolvidas para elas se tornam, assim, instrumentos de dominação.

Enquanto encontros mediados e ao vivo são obviamente muito diferentes em alguns aspectos, eles podem ser analisados usando princípios semelhantes. Os padrões de informação de fluxo, direta ou mediada, ajudam a definir a situação e as noções de estilo e ação apropriada (MEYROWITZ, 1985). Dessa forma, para compreender a situação social criada a partir do porte de uma determinada TDIC, dependerá exatamente pensar em todos os elementos que formam o palco e os bastidores onde serão exercidos os papéis do professor e do aluno e organizar isso. 
Por isso tudo, repensar a escola é refletir o significado da instituição para os adolescentes constantemente bombardeados pelo conteúdo cibernético e mediados por TDIC. Seus dispositivos móveis recebem constantes inovações e melhorias orientadas por esse mercado e estão se tornando imprescindíveis para diversas atividades diárias, porque as funcionalidades do aparelho respondem à praticidade do uso. Os motivos para os usos dos dispositivos móveis - as mais recentes tecnologias acessíveis a um grande número de adolescentes - ampliam-se à medida que consumidores exigem.

Conforme o panorama de Charlot (2014) e Castells (2001), a escola hoje sofre de problemas estruturais com base na lógica da modernização e no neoliberalismo que explicam, em parte, o problema que se reflete nas salas de aula. Os conceitos de eficiência e eficácia desejáveis à busca da qualidade também no ensino entram em conflito com as características funcionais da escola.

Portanto, é bastante desafiador proibir o uso de tecnologias que atendem cada vez mais a necessidades de quem as utiliza, integrando-se às diversas atividades socioculturais. O problema parece pressionar o professor que tem desenvolvido táticas de relacionamento com os adolescentes para driblar o suposto descontrole em aula.

Por outro lado, as mídias, agora compiladas em dispositivos únicos, fazem urgir perspectivas de teóricos do meio e das mídias como nunca antes, pois compreender os processos como a comunicação ocorre não só explica as influências que as mídias exercem em novas gerações, como também explica a própria comunicação que ocorre nas interações entre alunos e professores que, aos poucos, são, também, dessas novas gerações.

\section{SOBRE TDIC NAS ESCOLAS E DISPOSITIVOS MÓVEIS EM AULA}

No espaço escolar, de onde foram coletados os dados, os adolescentes têm duas possibilidades de acesso à Internet: o laboratório de informática do programa ProInfo ${ }^{7}$, e os seus dispositivos móveis, sejam eles: tablets, notebooks, netbooks, principalmente, os celulares com internet.

\footnotetext{
7 O ProInfo [Integrado] é um programa de formação voltada para o uso didático-pedagógico das Tecnologias da Informação e Comunicação (TIC) no cotidiano escolar, articulado à distribuição dos equipamentos tecnológicos nas escolas e à oferta de conteúdos e recursos multimídia e digitais oferecidos pelo Portal do Professor, pela TV Escola e DVD Escola, pelo Domínio Público e pelo Banco Internacional de Objetos Educacionais. Segundo Fiorentini (2008), é um programa educacional com o objetivo de promover o uso pedagógico da informática na rede pública de Educação Básica. O programa leva às escolas computadores, recursos digitais e conteúdos educacionais. Em contrapartida, Estados, Distrito Federal e municípios devem garantir a estrutura adequada para receber os laboratórios e capacitar os educadores para o uso das máquinas e das tecnologias.
} 
Estes últimos são de alta mobilidade entre os dispositivos e não são usualmente considerados nos programas escolares como recurso didático. Sua vantagem é pronto acesso, caso haja conexão disponível; atualmente; disponíveis são o sistema de terceira e quarta ( $3 \mathrm{G}$ e $4 \mathrm{G}$, respectivamente) para aqueles que pagam planos de operadoras de internet.

Algumas operadoras disponibilizam acesso em plano pré-pago, mas o uso de dados é bem limitado. O acesso não chega a dez páginas e sequer dá andamento pleno a um vídeo online.

No entanto, os adolescentes conseguem trocar diversas mensagens nas redes sociais, embora não possam trocar muitos arquivos e nem abrir muitas fotos, por conta dessa limitação de dados das operadoras.

Entre as formas de comunicação, além das redes sociais, os adolescentes usam o Whatsapp Messenger. O Whatsapp é um aplicativo multiplataforma de mensagens instantâneas e chamadas de voz para smartphones.

Seu sistema operacional é FreeBSB, um tipo de Unix, descendente do BSB, cujo código aberto é o mais usado e foi desenvolvido pela Universidade da Califórnia, em Berkeley.

Além de mensagens de texto, os usuários podem enviar imagens, vídeos e documentos em Portable Document Format (Formato Portátil de Documento ou pdf), além de fazer ligações grátis por meio de uma conexão com a internet. Sistema robusto, apresenta excelente estabilidade na conexão e na troca de mensagens.

A forma de comunicação preferida pelos adolescentes que portam celular com internet tem sido essa, quando conseguem algum tipo de acesso. Este seria um exemplo muito bom de social media que não sofre a influência de algoritmos, sendo assim, um bom instrumento mediador para professores.

$\mathrm{Na}$ escola, a banda larga é disponibilizada apenas para os computadores do prédio, entre eles os do laboratório de informática dos alunos. Nas escolas visitadas, o acesso no horário de intervalo é permitido. Portanto, por não haver acesso wi-fi permitido pelas instituições escolares, os adolescentes acessam em aula nesse contexto acima descrito.

Para além da conexão, o uso dos celulares serve para ver horas, calcular e mais inúmeras outras funções oferecidas por aplicativos disponíveis no mercado, sendo centenas deles distribuídos gratuitamente. Lembrando que, em aula, há professores que proíbem os celulares em sala. Ao mesmo tempo, podemos entender que os próprios professores usam eventualmente esse recurso, junto aos alunos. 
Pensando nesses dispositivos de comunicação como criadores de situações sociais paralelas em uma situação social hierarquizada por níveis de conhecimento, temos, além da tendência de uma quebra das regras de não uso por aqueles que usam intensivamente, a quebra também da situação de segregação entre os níveis do professor e do aluno.

Há, segundo Meyrowitz (1985), um enfraquecimento dos grupos de identidade quando os back region dos grupos são expostos pelos meios eletrônicos. Entretanto, o back region de um professor que pode ser exposto a um aluno está no ciberespaço na forma de redes sociais, quando o professor participa delas (mas, nesse caso, ainda, é controlável pelo professor) ou no saber disponível aos alunos em bibliotecas online, blogs ou sites especializados e vídeos, explicando as matérias das mais variadas disciplinas.

Os professores que não dominam esse conteúdo cibernético e que acreditam na “instrução" em vez da "construção do conhecimento" sentem perder o controle que supostamente seriam deles na sala de aula. Nesse processo, pode-se imaginar uma parte do conflito em lidar com as TDIC.

Portanto, embora o celular tenha classificação de alta mobilidade e seja possível deparar-se com inúmeros adolescentes que possuem esse dispositivo, não há tanta afirmação de seu uso para fins de pesquisa ou estudo em aula, dadas as condições do embate aluno versus escola com sua estrutura e práticas.

Nesse caso, proibir, aparentemente, torna mais difícil a interação professor-aluno. Se o uso é muito intensivo, o aluno tende a usar em aula para diversos fins por força do hábito, a despeito de proibições. Por outro lado, segundo os professores, os alunos não prestam mais atenção, principalmente porque suas disciplinas competem com os dispositivos móveis trazidos pelos adolescentes.

Segundo essa lógica, dispositivos móveis são um problema real: quanto mais funções nos aparelhos, mais chances de o aluno se dispersar durante a aula. Na maioria das escolas, o treinamento para lidar com as TDIC integrando à disciplina é insuficiente, quando há. Há mais discussão sobre as TDIC nas escolas privadas do que nas públicas. Aliás, não há ou ao menos é insuficiente ou não muito divulgado em alguns casos.

No que se refere ao uso dos dispositivos móveis em sala, considera-se que não há controle no conteúdo acessado, já que os alunos portam os próprios dispositivos e, quando usam a internet, acessam pouco conteúdo; contudo, é mais viável o uso da internet dos pacotes de dados dos celulares, já que esse uso é limitado. Além disso, as aulas são divididas por tempo de 50 minutos. 
Essa limitação do tempo de pesquisa e execução das tarefas em laboratório é um empecilho para os professores que enfrentam diversas restrições técnicas nos usos dos dispositivos digitais disponíveis nas escolas.

Portanto, se há um despreparo dos professores, isso se deve, em parte, a um desajuste no uso de TDIC nos laboratórios quanto à forma como eles controlam a sala neste contexto.

Nas dificuldades do embate entre professor e aluno no uso das TDIC, existe uma consciência da necessidade de integrá-las à didática, mas as dificuldades apresentam-se maiores diante do contexto, e a facilidade de proibir torna-se mais fácil a prazo imediato.

Embora exista o auxílio das TDIC para aprender, algumas vezes, vem a ser um engodo, já que os alunos postergam o aprendizado para depois das aulas, nem sempre uma realidade. Agrega-se, ainda, uma preocupação com o controle tradicional que, no fim, é decorrente do próprio sistema: "Aquilo que nos acalenta, são todos os vestibulares, todas as provas, elas são do modo tradicional" (Professor A).

Os professores se transformam em treinadores ou instrutores. Interpreta-se que o modo tradicional de disciplinar e avaliar o aluno é um norteador do trabalho deste professor, independentemente de ele ser mais flexível em relação às TDIC ou não.

Diante da finalidade de preparar cidadãos, pelo exercício da consciência crítica, temos um contexto que, mesmo com a inserção de técnicas e tecnologias, vê-se preso àquilo que se propõe em contradição: no grande sistema de recompensa, atrair a atenção daqueles que acreditam garantir sua posição no mercado de trabalho.

Entre os professores há aqueles que usam, efetivamente, e, com frequência, o laboratório. Um exemplo de como seria um trabalho que integra as TDIC à didática da disciplina, um professor de 28 anos que está aplicando uma pesquisa do seu curso de mestrado. Não é a regra.

Mas podemos aproveitar o relato do professor de matemática $\mathrm{B}$, que usa, frequentemente, o laboratório, para analisar as interações estabelecidas entre ele e os alunos, assim como analisar sua experiência de uso do laboratório, considerado, aqui, sala de aula.

Eu trabalho matemática com os alunos usando a WebQuest. Na verdade, faz parte do meu mestrado na USP. Eu tô aplicando nas escolas públicas. [...] Primero a gente fornece o conhecimento. Então o professor tem de pesquisar sobre os assuntos e trazer. É coisa bem do dia a dia. Tipo, a gente percebe que eles são muito consumistas, então eu tenho que ensinar matemática, mas tem esse problema, então para dar noção do que eles 
estão fazendo, dar essa consciência do consumismo, a gente ensina que as coisas não são bem assim (Professor B).

Conforme relato do professor B, a integração entre disciplina e TDIC ocorre de forma interativa ou construtivista e não instrucional, pois os alunos resolvem problemas contextualizados na plataforma educativa. A descrição do trabalho demonstra potencial para ultrapassagem dos limites de uma única disciplina. Mas a adaptação à situação social do professor demonstrou conflito:

\begin{abstract}
A ideia no final é fazer eles perceberem que o carro tem um gasto alto comparado num ano inteiro e também perceber que o carro popular gasta menos, consome menos e aí a ideia de poluir menos. Mas a professora de ciências tinha o mesmo problema que a de português. Foi uma que também para receber o tablet do Estado, tinha de fazer uma conta do gmail. E foi, tipo, um bafafá. Muito mais fácil com 30 alunos na sala, do que fazer com as professoras depois, sabe? E aí pintou esse medo. Eu tento inserir elas no meio e elas acabam, tipo, piorando a situação. Porque aí os "molequinhos" perdem o controle. E aí, eu tenho que assistir a aula delas. Fica difícil para eu poder avaliar como seria o trabalho delas (Professor B).
\end{abstract}

Professores de outras áreas que fariam parte do projeto que integra várias disciplinas na plataforma Webquest dificultaram a integração pelas suas próprias condições, e o professor B acabou limitado em sua atuação.

Nas escolas públicas, o uso do celular nas atividades de sala é um caminho de aproximação aos adolescentes. Associar o ensino ao uso de tecnologias passa não só pela pressão dos adolescentes em usar os dispositivos móveis em sala, como também pela dificuldade de usar os recursos oferecidos pelo governo. Entretanto, não existe a consciência de como fazer esse trabalho.

Semelhante situação é descrita por Porto (2012, p. 184) como "estratégias de sobrevivência", tanto na sala de aula quanto nos laboratórios de informática. “Percebemos que as professoras não se opõem às mudanças; elas as querem, porém utilizam as tecnologias [novas ou não] da forma como acreditam que devam ser utilizadas, o que, na maioria das situações não se configura em avanço ou inovação".

Sua observação remete à Charlot (2014, p. 50), quando diz que o professor aceita mudança e se esforça, mas, quanto mais difíceis as condições de trabalho, mais predominam os esforços para sobreviver, "esvaziando o sentido da inovação". 


\section{CONSIDERAÇÕES}

Pode-se entender que as contradições presentes ocorrem nos objetivos escolares e as dificuldades aumentam quando tentativas de inserção de TDIC ao ensino-aprendizagem se deparam com questões técnicas e de ajuste dos professores envolvidos.

Portanto, concordamos que as características de estrutura dificultam as mudanças e inovações, visto que os recursos ainda são escassos para a manutenção de programas como os oferecidos atualmente pelo governo.

Soma-se a isso a transição necessária de geração de professores que se dividem entre os que estão se aposentando, os que estão se adaptando e, ainda, aqueles da geração dos totalmente familiarizados com as TDIC.

Esse movimento de esforço se daria não apenas passível de uma ordem econômica, mas também coordenado com as questões sociais e subjetivas. Somente nos termos de um aprofundamento das técnicas de ensino mediadas e na observação das mudanças sociais com reflexão sobre subjetividades e potencialidades de jovens e de adolescentes é que se pode pensar na construção do conhecimento eficaz e eficiente real.

No que concerne ao desejo de disciplina em sala, pode-se dizer que a confusão dos professores, ao lidarem com os alunos que portam esses dispositivos, tem a ver muito com uma noção de controle característico dos tradicionais modos de ensinar, que se reduzem a transmitir informações.

Assim, se não sabem o que os alunos estão fazendo nos celulares enquanto explicam, se os alunos não estão atentos ao que falam, então, eles "perderam o controle”, pois os estudantes não estão no palco, mas nos bastidores.

O professor que acredita que seu papel é o de "instruir" enfrenta problemas, porque sente dificuldade em administrar a possibilidade que os alunos têm de saber algo antes que o conteúdo seja apresentado, de tal forma que eles não se interessem por suas aulas.

Nesse contexto, o controle da disciplina nos termos de instrução passa a ser trabalho hercúleo, pois, nos novos moldes de mediação, espera-se muito mais participação ativa do aluno. A duplicidade do que pode estar acontecendo com o estudante em relação à aula é, desde sempre, a mesma, com ou sem TDIC presentes.

$\mathrm{Na}$ cultura digital, as mídias podem afetar a definição de situações sociais, ignorando restrições físicas tradicionais sobre o fluxo de informações. Essas mudanças afetam o modo como as pessoas se comportam, ou melhor dizendo, como essas pessoas exercem seus papéis sociais. 
Além disso, dispositivos digitais, sites, redes sociais, plataformas etc. podem ser cuidadosamente construídos com base em planejamento que prevê o controle daquilo que será veiculado, ainda que esta construção seja baseada, inicialmente, em preferências do usuário, mas nem sempre. Esta exceção é que deve ser conhecida pelo professor que escolhe seus recursos tecnológicos para integração à didática.

O campo de atuação do professor em meios às TDIC passa por diversos níveis, e uma atualização constante sobre como eles funcionam e se modificam será sempre necessária a partir de agora na cultura digital. Caso contrário, o professor corre risco de não poder exercer a efetiva qualidade de que trata Charlot, ao propor uma visão que ultrapasse o liberalismo, e o que aborda Saviani, quando propõe uma mudança na educação em direção à emancipação e à cidadania.

Recebido em: 25-03-2018 Aceito em: 21-06-2018

\section{REFERÊNCIAS}

BÉVORT, E.; BELLONI, M. L. Media education: concepts, history and perspectives. Educação \& Sociedade, v. 30, n. 109, p. 1081-1102, 2009.

BÉVORT, Evelyne; BELLONI, Maria Luiza. Media education: concepts, history and perspectives. Educação \& Sociedade, v. 30, n. 109, p. 1081-1102, 2009.

CASTELLS, M. A Era da Informação: economia, sociedade e cultura. Vol. I: Sociedade em Rede. $5^{\text {a }}$ ed. São Paulo: Paz e Terra, 2001.

CASTELLS, M. O poder da identidade. São Paulo: Paz e Terra, p. 21-92, 1999.

CHARLOT, B. O professor na sociedade contemporânea: um trabalhador da contradição. Revista da FAEEBA - Educação e Contemporaneidade, Salvador, v. 17, n. 30, p. 17-31, 2008.

CHARLOT, B. Da relação com o saber às práticas educativas. Cortez Editora, 2014. Versão Kindle.

DESSEN, M. A.; POLONIA, A. A família e escola como contextos de desenvolvimento humano. Paidéia, v. 17, n. 36, p. 21-32, 2007.

FANTIN, M.; RIVOLTELLA, P. C. Cultura Digital e Escola: pesquisa e formação de professores. $1^{\text {a }}$ Ed, São Paulo: Papirus, 2012.

FIORENTINI, L. M. R. Introdução à educação digital: guia do formador. Brasília: MEC/SEED, 2008. Disponível em: <http://webeduc.mec.gov.br/Proinfointegrado/Material\%20de\%20Apoio/apostila_press.pdf>. Acesso em: 30 set. 2013. 
GONNET, J; BELLONI, M.L. Educação e mídia. São Paulo: Edições Loyola, 2004.

MEYROWITZ, J. No sense of place: the impact of electronic media on social behavior. London: Oxford University Press, 1985.

PORTO, T. M. E. As tecnologias estão nas escolas. E agora, o que fazer com elas? In: Cultura digital e escola: pesquisa e formação de professores. Papirus: São Paulo, 2012. p. 167-194.

SANTAELLA, L. Comunicação ubíqua: repercussões na cultura e na educação. São Paulo: Paulus, 2013. Versão Kindle.

SAVIANI, Dermeval. Democracia, educação e emancipação humana: desafios do atual momento brasileiro. Psicologia Escolar e Educacional, v. 21, n. 3, p. 653-662, 2017.

SAVIANI, Dermeval. Escola e democracia. Campinas: Autores Associados, 1999.

TOMMASI, L. de; WARDE, M. J.; HADDAD, S. O Banco Mundial e as políticas públicas educacionais. São Paulo: Cortez, 2000. 